\title{
Congenital Malformations Induced by Rabbit Antiserum against Rat Placental Glycoproteins Isolated by Concanavalin A Affinity Chromatography. Teratogenic Antibodies are Not Nephrotoxic
}

\author{
CHRISTOPHER C. K. LEUNG ${ }^{(18)}$ \\ Department of Anatomy, Louisiana State University School of Medicine, Shreveport, Louisiana, USA
}

\begin{abstract}
Summary
Previous investigations concerning the biologic effects of heterologous antisera raised against rat chorioallantoic placenta demonstrated that the antisera were nephrotoxic, abortifacient, and teratogenic. It is important to determine if maternal nephritis is associated with abnormal embryonic development induced by antiplacenta sera. In this report, a soluble glycoprotein fraction was isolated from rat chorioallantoic placentas of day 16 of gestation by concanavalin $A$ affinity chromatography after solubilizing the saline-washed placental sediment by sodium deoxycholate. Antiserum raised against this soluble glycoprotein fraction induced abnormal embryonic development when the antiserum was injected intraperitoneally into 9th day pregnant rats. The teratogenic effect of the antiserum was dose-dependent. The most frequently observed congenital defect was anophthalmia. Examination of the teratogenic antiserum for nephrotoxicity was performed by measuring the daily urinary protein output of the injected animals and by examining the ultrastructural morphology of the renal glomeruli after the injection of the antiserum into male and pregnant rats. The data indicated that the teratogenic antiserum was not nephrotoxic and therefore support the view that abnormal embryonic development does not result from maternal Masugi nephritis in this experimental model. In vivo immunofluorescent studies demonstrated that the antibodies to the placental glycoproteins localized primarily in the visceral yolk-sac endodermal cells and in Reichert's membrane, which is the basement membrane of the parietal yolk-sac. It is postulated that the antiserum might induce abnormal embryonic development by interfering with the normal functions of the yolk-sac placenta.
\end{abstract}

\section{Speculation}

Data obtained from this study suggest that different antibodies may be involved in nephrotoxic serum nephritis (Masugi nephritis) and experimental production of congenital malformations induced by heterologous antirat placenta antiserum. The teratogenic antibodies against the glycoprotein fraction obtained by concanavalin A affinity column were not nephrotoxic. The teratogenic antibodies may crossreact with antigens in Reichert's membrane and the visceral yolk-sac endodermal cells. It is possible that the teratogenic antibodies may induce abnormal embryonic development by interfering with the normal functions of the yolk-sac placenta.

Dobrowolski (5) first showed that heterologous antisera against chorioallantoic placenta, produced in the goat, interrupted pregnancy in guinea pigs and rabbits. Later in a series of papers, Seegal and Loeb $(13,14)$ and Loeb and Seegal (11) reported resorption of rat fetuses and the development of nephritis in the mothers when rabbit antirat placenta serum was administered to pregnant rats. In 1961, Brent and his colleagues (3) first reported that intraperitoneal injection of rabbit antiserum against rat kidney homogenate to pregnant rats during the organogenetic period produced congenital malformations. After this publication, Brent (4) and Nemirovsky (12) reported that heterologous antisera directed against chorioallantoic placenta also induced abnormal embryonic development. The underlying mechanism whereby teratogenic antisera induces abnormal embryonic development is not understood. It is well established that heterologous antiserum directed against rat placental homogenate crossreacts with renal antigens. The injection of heterologous antiplacenta serum will lead to a glomerulopathy similar to that of Masugi nephritis (15). The previous two investigations $(4,12)$ on teratogenesis induced by placental antisera utilized whole placenta homogenate; the responsible placental antigens that elicit the production of teratogenic antibodies have not been identified. The important relationship between teratogenesis and maternal nephritis induced by antiserum against placenta has not been determined. This communication reports on the isolation of a soluble glycoprotein fraction from rat chorioallantoic placenta using detergent sodium deoxycholate and concanavalin A (Con A) affinity chromatography. The rabbit antiserum raised against this placental glycoprotein fraction was teratogenic, but not nephrotoxic.

\section{MATERIALS AND METHODS}

Timing of pregnancy. Randomly bred Wistar rats were mated $12 \mathrm{~h}$ overnight. Females that had been inseminated were considered to be $0 \mathrm{~h} 0$ days pregnant at 9:00 a.m. the next morning or at the beginning of the lst day of pregnancy. Rats were housed in stainless steel cages and given food (Purina Mouse Chow) and water ad libitum.

Isolation of soluble glycoprotein antigens. Rat chorioallantoic placentas were removed from rats in their 16th day of gestation. Visceral yolk-sacs and remnants of Reichert's membrane, which might still attach to the placentas were carefully removed surgically from the fetal surface of the placentas. The placentas were immediately frozen and stored at $-60^{\circ} \mathrm{C}$. One hundred frozen placentas were utilized for each experiment. They were taken out from the deep freeze and homogenized immediately in phosphatebuffered saline (PBS) in a Virtis " 45 " homogenizer (Virtis Company, NY) for $10 \mathrm{~min}$ at $4^{\circ} \mathrm{C}$. The homogenate was then centrifuged at $40,000 \times g$ for $1 / 2 \mathrm{~h}$ at $4^{\circ} \mathrm{C}$. The supernatant was removed and the residual pellet was washed again by homogenizing in PBS as before. The supernatant resulting from the second homogenization and centrifugation was combined with the first supernatant, dialyzed against distilled water and lyophilized. The washed placental residue was extracted with $100 \mathrm{ml}$ of $0.1 \mathrm{M}$ Tris- $\mathrm{HCl}$ buffer $\mathrm{pH} 8.0$ containing $1 \%$ sodium deoxycholate for $2 \mathrm{~h}$ with constant 
stirring at room temperature. The treated mixture was centrifuged at $40,000 \times g$ for $1 / 2 \mathrm{~h}$. The clear supernatant was recovered and dialyzed extensively against the $0.1 \mathrm{M}$ Tris- $\mathrm{HCl}$ buffer for 5 days with daily changes of buffer. The dialysate was centrifuged at $40,000 \times g$ for $1 / 2 \mathrm{~h}$. and concentrated to about $20 \mathrm{ml}$ by an Amicon ultrafiltration unit fitted with a PM 10 membrane. The concentrate from the Amicon ultrafiltration unit was clarified by centrifugation at $2000 \times g$. The clear supernatant was applied onto a Con A-Sepharose 4B column prepared as follows. Con A covalently bound to Sepharose 4B was obtained from Pharmacia (Uppsala, Sweden). One $\mathrm{ml}$ of packed Sepharose 4B contained approximately $10 \mathrm{mg}$ of Con A. Twenty-five $\mathrm{ml}$ of Con A-Sepharose 4B was equilibrated with $0.1 \mathrm{M}$ Tris- $\mathrm{HCl} \mathrm{pH} 8.0$ buffer and packed into a glass column $(15 \times 150 \mathrm{~mm})$. The equilibrated protein concentrate was allowed to pass through the Con A-sepharose $4 \mathrm{~B}$ column at a flow rate of $5 \mathrm{ml} / \mathrm{h}$ at room temperature. The column was then washed with the same buffer until the absorption of the effluent at $280 \mathrm{~nm}$ decreased to almost the buffer level. The absorbed glycoproteins were eluted by the addition of the same buffer containing $0.1 \mathrm{M} \alpha$-methyl-D-mannoside. The eluted glycoproteins were dialyzed against distilled water for 3 days with multiple changes of distilled water, and then lyophilized.

Production of rabbit antiserum. New Zealand white female rabbits weighing about $2.5 \mathrm{~kg}$ each were utilized for the production of antisera by the method described previously (10). The two lyophilized placental protein fractions, PBS-extract and glycoproteins eluted from Con A column, were reconstituted with a small volume of PBS. Ten mg of lyophilized proteins were used for each immunization. Rabbits were initially immunized in the footpads. Subsequent subcutaneous injections were given weekly for $6 \mathrm{wk}$. Rabbits were bled after the fourth immunization. Rabbit antiserum was similarly produced against Con A (Sigma Company). Antibody titers of the antisera were monitored by double immunodiffusion in gel.

Bioassay of antisera for teratogenicity. Teratogenicity testing of the antisera was performed in the following manner. On the 9 th day of gestation, pregnant rats were injected intraperitoneally with $10 \mathrm{ml} / \mathrm{kg}$ of various experimental and control antisera. All rats were anesthetized with sodium pentobarbital $(30 \mathrm{mg} / \mathrm{kg})$. Another group of pregnant rats were injected with preimmunization rabbit serum as controls. The mothers were sacrificed on the 22 nd day of gestation and the fetuses were delivered by caesarean section. The fetuses were examined grossly, weighed, and fixed in Bouin's fixative for dissection. The incidence of malformations was determined by the cross-sectional technique of Wilson (16).

Determination of nephrotoxicity of teratogenic antiserum. The nephrotoxicity of the teratogenic antiserum was evaluated by its ability to induce proteinuria when injected into male rats and rats of 9 th day pregnancy. The procedure is the same as previously reported (10). Two ml of antiserum were injected intraperitoneally under light phenobarbital anesthesia. Twenty-four $h$ urine samples were collected for the first 2 days and then 13 days postinjection. The protein content of the urine was determined according to the method of Kingsburg et al. (7). For examination by electron microscope of renal glomeruli of injected animals, renal cortical tissues were doubly fixed in $3 \%$ glutaraldehyde in $0.1 \mathrm{M}$ phosphate buffer, $\mathrm{pH} 7.4$ and $1 \%$ osmium tetroxide in $0.1 \mathrm{M}$ phosphate buffer, $\mathrm{pH} 7.4$, dehydrated in graded ethanols through propylene oxide and embedded in Epon 812. Thick sections were examined after staining in $1 \%$ toluidine blue- $1 \%$ sodium borate. Ultrathin sections were stained with uranyl acetate and lead citrate.

Immunofluorescent localization of teratogenic antiserum. After the intraperitoneal injection of teratogenic antiserum into pregnant rats on the 9th day of pregnancy, the mothers were sacrificed $48 \mathrm{~h}$ later. Maternal kidneys and embryonic tissues were examined for the in vivo localization of the injected antibodies with the direct fluorescent antibody technique as previously reported (10). Goat antirabbit immunoglobulins were purchased from Behring Diagnostics (Sonerville, NJ). Control rats were injected with preimmunization rabbit serum.

\section{RESULTS}

Teratogenicity testing. The results of testing for teratogenicity of the various rabbit antisera on embryonic development are summarized in Table 1. When administered to rats on the 9th day of gestation, the antiserum raised against the glycoprotein fraction obtained by Con A affinity chromatography was teratogenic. Intraperitoneal injection of $1 \mathrm{ml}$ of antiserum per $100 \mathrm{~g}$ of pregnant rat induced abnormal embryonic development in about $77 \%$ of all the surviving fetuses. The spectrum of malformations was similar to the original report of Brent (4) using antisera against whole rat placenta or fetal placenta. The teratogenic effect of the antiserum was dose-dependent. Lower dosage of antiserum induced lower $\%$ of fetuses with defects. The most frequently observed congenital defect was anophthalmia, although hydrocephaly and exencephaly were often observed. Preimmunization rabbit serum and antisera raised against Con A and the PBS-extract of the chorioallantoic placenta appeared to have little effect on embryonic development (Table 1).

Nephrotoxic studies of teratogenic antiserum. The antiserum raised against the glycoprotein fraction isolated by Con A affinity chromotography did not induce proteinuria in either pregnant rats or male rats. The results are summarized in Table 2 . The heterologous and autologous phases of kidney damage appeared to be absent after the administration of the antiserum since proteinuria was not observed for the first 13 days after antiserum administration. The amount of 24-h urinary protein output per experimental rat was not much higher than that of the control rat and it was significantly lower than the $200 \mathrm{mg} / \mathrm{day} / \mathrm{rat}$ generally considered to manifest proteinuria (10). Electron microscopic examination of the rat kidney 13 days after the injection of the teratogenic antiserum also confirmed the negative finding in proteinuria study. Only about $7 \%$ of all the foot processes of the epithelial cell adjacent the glomerular basement membrane were fused. There was no generalized thickening of the glomerular basement membrane. The endothelial fenestration also appeared to be normal.

In vivo immunofluorescent localization studies. When 9th day pregnant rats were injected with $10 \mathrm{ml}$ of teratogenic antiserum per $\mathrm{kg}$ of pregnant rat, specific immunofluorescent localization was observed in Reichert's membrane of the parietal yolk-sac placenta and in the visceral yolk-sac endodermal cells (Fig. 1).

Table 1. Summary of teratogenic testing

\begin{tabular}{|c|c|c|c|c|c|c|}
\hline \multirow[b]{2}{*}{ Antisera injected } & \multirow[b]{2}{*}{$\begin{array}{l}\text { No. of } \\
\text { litters }\end{array}$} & \multirow{2}{*}{$\begin{array}{c}\text { MI of } \\
\text { antisera } \\
\text { per kg of } \\
\text { pregnant rat }\end{array}$} & \multirow[b]{2}{*}{$\begin{array}{c}\text { No. of } \\
\text { implantation }\end{array}$} & \multirow[b]{2}{*}{$\begin{array}{c}\% \\
\text { resorption }\end{array}$} & \multicolumn{2}{|c|}{ Surviving fetuses } \\
\hline & & & & & Number & $\begin{array}{c}\text { \% with } \\
\text { malformations }\end{array}$ \\
\hline \multirow{2}{*}{$\begin{array}{l}\text { Antiserum to Glycoproteins Isolated by Con A affin- } \\
\text { ity column }\end{array}$} & 5 & 7.5 & 40 & 20.0 & 32 & 46.8 \\
\hline & 6 & 10 & 65 & 18.5 & 53 & 77.3 \\
\hline Antiserum to Con $\mathrm{A}$ & 9 & 10 & 108 & 12.5 & 95 & 1.1 \\
\hline Preimmunization rabbit serum & 9 & 10 & 94 & 9.6 & 85 & 1.2 \\
\hline
\end{tabular}


Table 2. Effects of antisera on rat urinary protein output

\begin{tabular}{|c|c|c|c|c|c|c|}
\hline \multirow[b]{2}{*}{ Rabbit antiserum } & \multirow{2}{*}{$\begin{array}{l}\text { No. of } \\
\text { rats } \\
\text { injected }\end{array}$} & \multicolumn{2}{|c|}{$\begin{array}{l}\text { Male rats } \\
\text { 24-hour urinary protein }\end{array}$} & \multirow{2}{*}{$\begin{array}{c}\text { No. of } \\
\text { rats } \\
\text { injected }\end{array}$} & \multicolumn{2}{|c|}{$\begin{array}{l}9 \text { th day pregnant rats } \\
24-h \text { urinary protein }\end{array}$} \\
\hline & & $\begin{array}{l}\text { lst day } \\
\text { postinjection }\end{array}$ & $\begin{array}{l}13 \text { days } \\
\text { postinjection }\end{array}$ & & $\begin{array}{l}\text { 1st day } \\
\text { postinjection }\end{array}$ & $\begin{array}{l}13 \text { days } \\
\text { postinjection }\end{array}$ \\
\hline $\begin{array}{l}\text { Antiserum to glycoproteins isolated by Con A affin- } \\
\text { ity chromatography }\end{array}$ & 10 & $16 \pm 7^{1}$ & $25 \pm 9$ & 10 & $21 \pm 4^{1}$ & $19 \pm 8$ \\
\hline Control-preimmunization rabbit serum & 10 & $11 \pm 6$ & $14 \pm 7$ & 10 & $10 \pm 6$ & $12 \pm 6$ \\
\hline
\end{tabular}

'Average $\mathrm{mg} \pm$ S.D., (S.D., standard deviation).

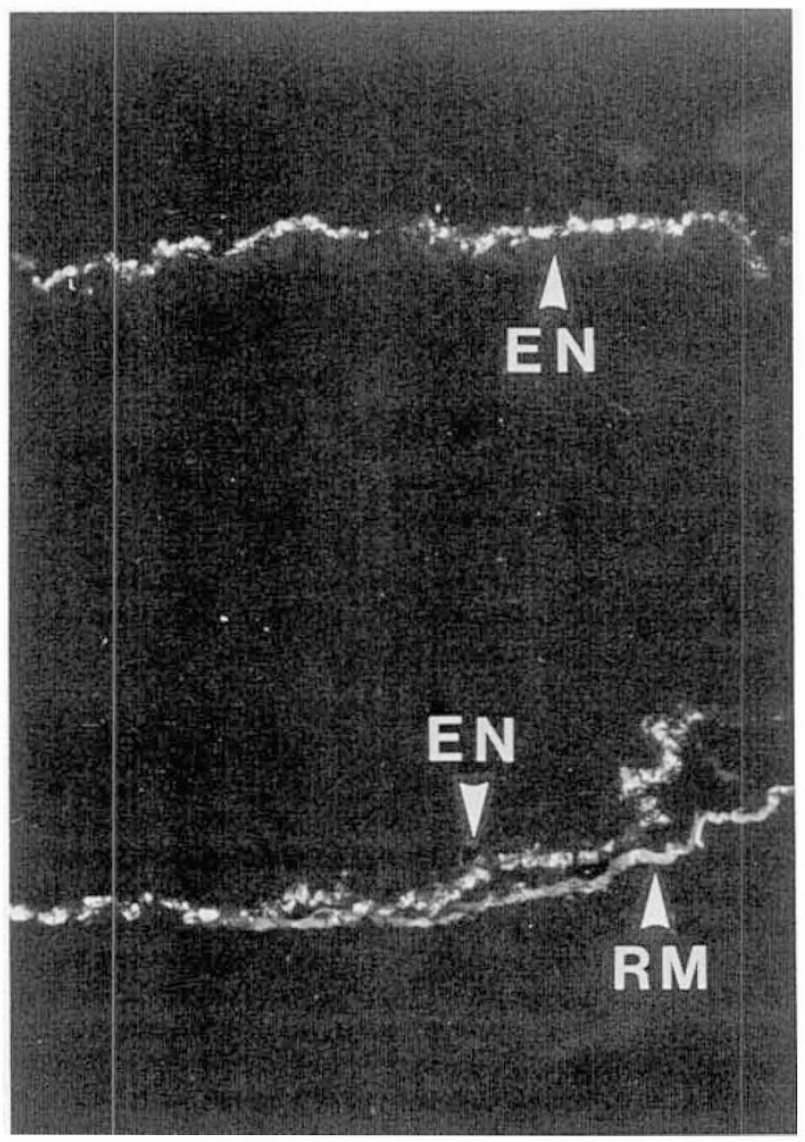

Fig. I. In vivo immunofluorescent localization of rabbit $\gamma$-globulin in th visceral yolk sac endoderm and Reichert's membrane. Embryonic tissue was examined 2 days after injection of teratogenic rabbit antiserum against the placental glycoproteins into a 9th day pregnant rat. Reichert's membrane (RM) and the visceral yolk sac endodermal cells (EN) are indicated by pointers $(\times 140)$.

Reichert's membrane was stained linearly whereas granular staining was observed at the apical part of the visceral yolk-sac endodermal cells (Fig. 1). There was little detectable fluorescent staining in the embryo proper, however, the maternal renal glomerular basement membrane appeared to be slightly fluoresced.

\section{DISCUSSION}

The biologic effects of heterologous antisera raised against whole chorioallantoic placenta are most intriguing. It is generally agreed that these antisera are abortifacient $(5,8,14)$, nephrotoxic (11, 13, 14) and teratogenic (4, 12). Some experimental data attempting to clarify these biologic effects have been documented. Gang and his associates (6) isolated an insoluble trophoblast basement membrane glycoprotein fraction from rat chorioallantoic placentas. The antiserum raised against this glycoprotein fraction was nephrotoxic but did not seem to interrupt pregnancy. These authors concluded that other antibodies rather than the antibodies raised against this basement membrane glycoprotein fraction appeared to be responsible for immune abortion (6). The antisera raised against trophoblast cells have been attributed by other investigators to be responsible for interrupting pregnancy $(1,8)$. Our present investigation described the isolation of a soluble glycoprotein fraction from rat chorioallantoic placenta by detergent DOC and Con A affinity column. Although this was not a homogeneous glycoprotein antigen (at least three antigens were observed by double immunodiffusion analysis) it represented a better defined antigenic fraction than whole placental homogenate, which was previously utilized by other investigators $(4,12)$. The results of this present investigation support the view that immunologically induced teratogenesis by antiplacenta serum does not result from maternal Masugi nephritis. In other studies utilizing heterologous antikidney antiserum, Leung and his associates $(9,10)$ presented both direct and indirect evidence that different antibodies are involved in the production of immunologically induced teratogenesis and nephritis.

The pathophysiologic mechanism whereby heterologous antisera induced teratogenesis is not understood. Three hypotheses have been proposed (2). They are: (1) a direct effect of antibodies on the embryo proper; (2) secondary effect due to immunologic disease of the mother, and (3) chorioallantoic or yolk-sac placental dysfunction. Although better understanding of the mechanism would come from the isolation of a population of monospecific teratogenic antibodies, the results of our present in vivo immunofluorescent localization study seems to focus our attention onto the yolk-sac placenta, specifically the visceral yolk sac endoderm and Reichert's membrane of the parietal yolk sac. It is possible that antibodies directed against the chorioallantoic placental glycoprotein fraction crossreacted with antigens in the visceral yolk sac endoderm and Reichert's membrane. Teratogenesis could result from antibody-antigen interaction within Reichert's membrane and visceral yolk sac endoderm, thereby interfering with the normal functions of the yolk sac placenta.

\section{REFERENCES AND NOTES}

1. Beer, A. E., Billingham, R. E., and Yang, S. L.,: Further evidence concerning the autoantigenic state of the trophoblast. J. Exp. Med., 135: 808 (1972).

2. Bragonier, J. R., Frank, M. M., and Brent, R. L.,: Production of congenital malformations using tissue antisera. VIII. Effectiveness of reduced, alkylated and digested anti-kidney antibodies. J. Immunol., 105: 1175 (1970).

3. Brent, R. L., Averich, E., and Drapiewski, V. A.,: Production of congenital malformation using tissue antibodies. I. Kidney antisera. Proc. Exp. Biol. Med., 106: 523 (1961).

4. Brent, R. L.,: The production of congenital malformation using tissue antisera III. Placenta antiserum. Proc. Soc. Exp. Biol. Med., 125: 1024 (1967).

5. Dobrowolski, M. S.,: Uber cytotoxine der plazenta. Bull. Int. Acad. Sci. Cracovie. 5: 256 (1903).

6. Gang, N. F., Schwartz, E. S., Majerovics, A., DeChamplain, M. L., and Trachtenberg, E..: Studies on the placenta. II. Nephrotoxicity of antibodies produced against a chorionic glycoproteins. Amer. J. of Obs. Gynecol., 120: 72 (1974).

7. Kingsburg, F. B., Clark, C. P., Williams, G., and Post, A. L..: The rapid determination of albumin in urine. J. Lab. Clin. Med., 11: 981 (1926).

8. Koren, Z., Abrams, G., and Behrman. S. J.,: Antigenicity of mouse placenta tissue. Amer. J. Obs. Gynecol., 102: 340 (1968).

9. Leung, C. C. K. and Brent, R. L.,: The production of congenital malformations using tissue antisera. X. Effectiveness of kidney antigens treated with neuraminidase or trypsin. Pediatr. Res., 6: 822 (1972).

10. Leung, C. C. K., Urdaneta. A., Jensh, R. P., Jensen. M., and Brent, R. L.,: Evidence that different antibodies are involved in the production of immunologically induced teratogenesis and nephritis. J. Immunol., 113: 885 (1974).

11. Loeb, E. N. and Seegal. B. C..: The production of chronic nephritis in rat 
following the initial injection of antiplacenta serum. Pathological findings. Fed. Proc., 2: 99 (1943).

12. Nemirovsky, M. S.,: The induction of congenital abnormalities in mice by means of heterologous anti-mouse placenta serum. Experientia, 26: 1138 (1970).

13. Seegal, B. C. and Loeb, E. N.,: Effect of anti-placenta serum on development of the fetus in the pregnant rat. Exp. Biol. Med., 45: 248 (1940).

14. Seegal, B. C. and Loeb, E. N.,: Porduction of chronic glomerulonephritis in rats by injection of rabbit anti-rat placenta serum. J. Exp. Med., 84: 211 (1946).

15. Unanue, E. R. and Dixon, F. J.,: Experimental glomerulonephritis: immunological events and pathogenetic mechanisms. In Advances in Immunology. Edited by F. J. Dixon and H. H. Humphrey. p. 1 (Academic Press, New York, New York 1967).

Copyright $(1982$ International Pediatric Research Foundation, Inc. $0031 / 82 / 1611-0973 \$ 02.00 / 0$
16. Wilson, J. G.,: Embryological consideration in teratology. In Teratology: Principles and Techniques. Edited by J. G. Wilson and J. Warkany. p. 251. (University of Chicago Press, Chicago IL 1965).

17. The author acknowledges Miss Chu-sei Hong for her technical assistance and Mrs. Gloria Marshall for typing the manuscript. This work was supported by National Institutes of Health Research Grants HD 13939 and HD 13940.

18. Requests for reprints should be addressed to: Dr. Christopher C. K. Leung, Department of Anatomy, Louisiana State University School of Medicine, Shreveport, LA 71130.

19. Received for publication February 17, 1982

20. Accepted for publication May 9, 1982. 